\title{
Estimulação elétrica neuromuscular em cães com atrofia muscular induzida
}

[Neuromuscular electric stimulation in dogs with induced muscle atrophy]

\author{
C. Pelizzari $^{1}$, A. Mazzanti ${ }^{2 *}$, A.G. Raiser ${ }^{2}$, S.T.A. Lopes $^{2}$, D.L. Graça ${ }^{2}$, A.T. Ramos ${ }^{1}$, \\ F.Z. Salbego ${ }^{1}$, R. Festugatto ${ }^{1}$, D.V. Beckmann ${ }^{3}$, L.B. Souza ${ }^{3}$, M.G.M.C.M. Cunha ${ }^{3}$, \\ R.P. Santos ${ }^{3}$, B. Garmatz ${ }^{3}$, A.P. Silva ${ }^{3}$, D.A.F. Sturza ${ }^{3}$ \\ ${ }^{1}$ Aluno de pós-graduação - UFSM - Santa Maria, RS \\ ${ }^{2}$ Universidade Federal de Santa Maria \\ Avenida Roraima, 1000 \\ 97105-900 - Santa Maria, RS \\ ${ }^{3}$ Aluno de graduação - UFSM - Santa Maria, RS
}

\begin{abstract}
RESUMO
Empregou-se a estimulação elétrica neuromuscular (EENM) de baixa freqüência no músculo quadríceps femoral de cães com atrofia induzida e avaliou-se a ocorrência de ganho de massa nessa musculatura. Foram utilizados oito cães com pesos entre 15 e $30 \mathrm{~kg}$, distribuídos aleatoriamente em dois grupos denominados de I ou controle e II ou tratado. A articulação femorotibiopatelar esquerda foi imobilizada por 30 dias pelo método de transfixação percutânea tipo II, com retirada de aparelho de imobilização após esse período. Decorridas 48 horas da remoção, foi realizada a EENM nos cães do grupo II, cinco vezes por semana, com intervalo de 24 horas cada sessão, pelo período de 60 dias. Foram avaliadas a circunferência da coxa, a goniometria do joelho, a análise clínica da marcha, as enzimas creatina-quinase (CK) e aspartato-amino-transferase (AST) e a morfometria das fibras musculares em cortes transversais do músculo vasto lateral colhido mediante biópsia muscular. A EENM foi empregada no músculo quadríceps femoral na freqüência de $50 \mathrm{~Hz}$, duração de pulso de 300 milisegundos e relação de tempo on/off de 1:2. Quanto à morfometria das fibras do músculo vasto lateral, no grupo tratado houve aumento significativo $(\mathrm{P}<0,05)$ da área transversal aos 90 dias em relação ao dia zero. A EENM de baixa freqüência ocasiona hipertrofia do músculo vasto lateral em cães após a imobilização rígida temporária da articulação do joelho.
\end{abstract}

Palavras-chave: cão, imobilização, remobilização, goniometria, biópsia

\begin{abstract}
Low frequency neuromuscular electrical stimulation (NMES) was used on the femoral quadriceps of dogs with induced muscular atrophy and the occurrence of gain in mass in these muscles was evaluated. Eight dogs from 15 to $30 \mathrm{~kg}$ were randomly distributed in two groups named I, or control; and II, or treated. For the induction of muscular atrophy, the left femoral-tibial-patellar joint was immobilized for 30 days by percutaneous transfixation type II. After 30 days, the immobilization device was removed. The NMES treatment began 48 hours after the removal of the immobilization device of the dogs of group II, and it was carried out five times per week with an interval of 24 hours between each session, for 60 days. The following parameters were measured: thigh circumference, goniometry of the knee, clinical gait analysis, creatine kinase (CK) and aspartate aminotransferase (AST) enzymes, and morphometry of the muscular fibers in transversal cuts of the vastus lateralis muscle collected through muscular biopsy. The NMES was applied on the femoral quadriceps at a frequency of $50 \mathrm{~Hz}$, with pulse duration of 300 milliseconds, and the on/off time was at a proportion of 1:2. Regarding the morphometry of the vastus lateralis fibers, a significant increase $(P<0.05)$ in the transversal area of the treated group at 90 days was observed when
\end{abstract}

Recebido em 27 de abril de 2007

Aceito em 18 de dezembro de 2007

*Autor para correspondência (corresponding author)

E-mail: alexamazza@yahoo.com.br 
compared with that identified at the time of immobilization. Thus, it can be concluded that low frequency NMES brings about hypertrophy of the vastus lateralis muscle in dogs after temporary rigid immobilization of the knee joint.

Keywords: dog, immobilization, remobilization, goniometry, biopsy

\section{INTRODUÇ̃̃O}

A atrofia muscular pode ser o resultado do desuso prolongado de um membro em decorrência de afecções ortopédicas, neurológicas (Salter et al., 2003; Millis, 2004) e após procedimentos cirúrgicos que necessitam de imobilização articular prolongada (Morrissey et al., 1985; Appel, 1986), sendo observada tanto em animais (Millis, 2004) como em seres humanos (Gould et al., 1983; Gibson et al., 1988). Entre as seqüelas encontradas pode-se citar a diminuição da força muscular, instabilidade e rigidez articular (Gossman et al., 1986) e diminuição da síntese das proteínas musculares (Gibson et al., 1988).

A atrofia da musculatura da coxa e rigidez articular foi encontrada por Mazzanti et al. (2004) quando usaram a fixação esquelética externa temporária para a imobilização da articulação fêmorotibiopatelar em cães após artroplastia do joelho. Resultados semelhantes foram observados por Salbego (2006) ao empregarem o mesmo tipo de imobilização na reconstrução do ligamento cruzado cranial em cães.

A estimulação elétrica neuromuscular (EENM) é uma modalidade terapêutica utilizada na prevenção da atrofia muscular por desuso (Johnson et al., 1997; Salter et al., 2003) para promover aumento da taxa de movimentação e força muscular, reeducação muscular, correção de anormalidades estruturais, melhora no tônus muscular, aumento da função, controle da dor, aceleração do processo de cicatrização, redução de edema e espasmo muscular, e administração transdérmica de medicamentos (Johnson e Levine, 2004). O mecanismo de ação ocorre mediante estímulos elétricos terapêuticos aplicados sobre o tecido muscular, por meio do sistema nervoso periférico íntegro (Brasileiro et al., 2002).

$\mathrm{Na}$ literatura consultada, verificou-se uma limitação no número de artigos científicos sobre o uso da EENM em cães que desenvolveram atrofia muscular por imobilização prolongada de uma articulação, tendo que recorrer, na maioria das vezes, a pesquisas realizadas em outras espécies, deixando dúvidas sobre a extrapolação da metodologia e dos resultados obtidos.

Os objetivos deste estudo foram avaliar a EENM de baixa freqüência sobre o músculo quadríceps femoral em cães após a atrofia muscular induzida pela imobilização rígida temporária da articulação do joelho e verificar a ocorrência de hipertrofia do vasto lateral por meio de biópsia muscular.

\section{MATERIAL E MÉTODOS}

Foram utilizados oito cães adultos, sem raça definida, machos ou fêmeas, com peso entre 15 e $30 \mathrm{~kg}$. Os animais receberam vermífugos à base de pamoato de pirantel/praziquantel na dose de $25 \mathrm{mg} \mathrm{kg}^{-1}$ de peso corporal, repetindo-se a mesma dosagem após 15 dias. Os cães foram submetidos à anestesia geral com tiopental sódico $\left(12,5 \mathrm{mg} \mathrm{kg}^{-1}\right)$ para estudo radiográfico simples da articulação coxofemoral e femorotibiopatelar em incidência ventrodorsal em busca de alterações articulares.

Os cães foram distribuídos ao acaso em dois grupos de igual número, denominados de grupo I ou controle e II ou tratado. Os do grupo II receberam tratamento de EENM por 30 minutos, uma vez ao dia, cinco vezes na semana, com intervalo de 24 horas entre as sessões. Durante dois dias consecutivos na semana, eram isentos do tratamento. As sessões foram realizadas até o $60^{\circ}$ dia após a remoção do fixador esquelético externo, com início das sessões 48 após a retirada. Os do grupo I receberam o mesmo tratamento com o aparelho de EENM desligado.

Em cada animal, foi realizada a tricotomia da coxa esquerda e estes foram pré-medicados com sulfato de morfina $\left(1 \mathrm{mg} \mathrm{kg}^{-1}\right)$ associado a maleato de acepromazina $\left(0,05 \mathrm{mg} \mathrm{kg}^{-1}\right)$. A anestesia, induzida com propofol $\left(4,0 \mathrm{mg} \cdot \mathrm{kg}^{-1}\right)$, foi mantida com halotano vaporizado em oxigênio a $100 \%$. A analgesia transoperatória foi 
assegurada com cloridrato de fentanila $(0,002 \mathrm{mg}$ $\left.\mathrm{kg}^{-1}\right)$. A anti-sepsia do campo operatório foi realizada com álcool-iodo-álcool e a administração de ampicilina sódica $\left(20 \mathrm{mg} \mathrm{kg}^{-1}\right)$ foi feita 30 minutos antes do início da cirurgia.

Após a contenção em decúbito lateral direito, foi realizada a biópsia muscular. Para tal, identificouse, por palpação, o músculo vasto lateral. A pele foi perfurada com uma agulha hipodérmica 16G. Em seguida, foi inserida no ventre muscular a agulha para biópsia do tipo tru-cut e removido um segmento muscular de aproximadamente

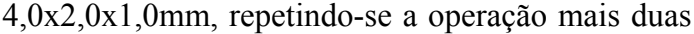
vezes. Os três fragmentos de músculos colhidos foram depositados em frasco estéril com formol para processamento histológico e posterior análise histomorfométrica. Esse procedimento foi realizado nos tempos zero (pré-imobilização), 30 dias (imediatamente após a retirada da imobilização) e 90 dias do procedimento de imobilização articular.

Para imobilização do joelho, foi efetuada a fixação externa percutânea biplanar ou tipo II, conforme descrito por Aron (1996), mantendo a articulação numa angulação de $90^{\circ}$, medida com o auxílio de um goniômetro. Como barra de conexão entre os pinos, foi utilizada resina acrílica autopolimerizável.

Os animais receberam como terapia antiinflamatória cetoprofeno $10 \%\left(2 \mathrm{mg} \mathrm{kg}^{-1}\right)$, por via subcutânea, durante três dias. A ferida de pele, provocada durante a biópsia muscular, foi higienizada com solução salina isotônica e protegida por esparadrapo hipoalergênico. As áreas de inserções dos pinos, na pele, foram higienizadas com solução salina isotônica, protegidas por gaze embebida em solução de nitrofurazona, e o aparelho de imobilização recoberto com atadura diariamente durante os 30 dias de imobilização.

Decorrido este período, os pinos que mantinham imobilizada a articulação do joelho foram removidos sob anestesia geral. Com o auxílio de um alicate específico, esses pinos foram higienizados e cortados em ambas as faces, aproximadamente $2,0 \mathrm{~cm}$ da pele e posteriormente tracionados. Em seguida, foi realizado curativo da área com solução salina isotônica e colocação de atadura de crepe.
A corrente emitida pelo aparelho ${ }^{1}$ de EENM tinha como característica onda pulsada unidirecional monofásica de baixa freqüência. Os parâmetros definidos no eletroestimulador foram freqüência de $50 \mathrm{~Hz}$, largura do pulso de 300 milissegundos, modo sincronizado, com ciclos de estimulação de 12 segundos seguidos por 25 segundos de descanso (relação on:off de 1:2). A rampa de subida (rise) e descida (decay) do pulso foi de três e cinco segundos, respectivamente. A intensidade de corrente ajustada no seletor do aparelho foi controlada de acordo com a tolerância do animal ao estímulo (vocalização, inquietude, retirada do membro estimulado).

Os músculos estimulados foram os que compõem o quadríceps femoral. Foi realizada a tricotomia da coxa esquerda e feita anti-sepsia com álcool para remoção da oleosidade e redução da resistência para passagem de corrente elétrica. Dois eletrodos de canais diferentes foram colocados sobre os pontos motores (Thomson e Bowen, 1971) do músculo vastomedial e vastolateral e os restantes situados sobre as mesmas musculaturas e o mais distante possível entre eles para fechamento de corrente numa disposição diagonal. Foi aplicado gel condutor apropriado de aproximadamente $3 \mathrm{~mm}$ de espessura sobre os eletrodos, posicionados conforme a técnica quadripolar (Kitchen, 2003) e fixados com fita elástica.

Com a coxa tricotomizada em ambos os membros pélvicos, e com auxílio de uma fita maleável de escala métrica graduada em centímetros, foram marcados três pontos eqüidistantes entre o trocânter maior e o côndilo lateral do fêmur realizando a mensuração da circunferência, para a obtenção de um valor médio. Com o auxílio de um goniômetro universal, foram mensuradas as angulações do joelho em flexão total e extensão total para se obter a limitação do movimento. Esses procedimentos foram realizados na pré e aos $30 \mathrm{e}$ 90 dias após a imobilização.

Após a remoção do aparelho de fixação externa tipo II, os cães foram avaliados segundo a adaptação à marcha. A recuperação do uso funcional do membro foi estimada clinicamente, mediante cinco graus: I - o paciente não usa e nem apóia o membro; II - usa e apóia não

${ }^{1}$ Neurodin N-43 - Ibramed - Amparo, SP - Brasil. 
freqüentemente o membro durante estação e, ao caminhar, não sustenta o peso no membro afetado elevando-se ao correr; III - usa claudicantemente o membro em estação e ao caminhar, sustenta parcialmente o membro, elevando-o ao correr; IV - caminha sem claudicar e posiciona-se normalmente o membro em estação, claudica ao correr sem elevá-lo; V usa funcionalmente o membro (Tudury e Raiser, 1985). Essa avaliação foi realizada pelo mesmo observador diariamente durante todo o período experimental e antes das sessões de EENM.

Foram coletados $5 \mathrm{ml}$ de sangue da veia jugular nos dias zero, 30, 45, 60, 75 e 90 de pósoperatório para obtenção do soro sangüíneo e avaliação da atividade das enzimas creatinaquinase (CK) e aspartato-amino-transferase (AST). Com exceção do dia zero, as coletas foram distribuídas em três tempos, ou seja, antes (T0), duas (T1) e seis (T2) horas após a primeira coleta.

Cada fragmento obtido na biópsia muscular foi fixado em formol, processado e corado pelo método de hematoxilina e eosina. Cada lâmina histológica foi confeccionada de acordo com o grupo e o período de coleta. Foram realizados estudos morfométricos em corte transversal das fibras musculares do vastolateral. Para isso, foram escolhidos, aleatoriamente, três locais de cada lâmina histológica, fotografados por uma câmera Olympus 220 acoplada ao microcópio Olympus BX50 com a objetiva de 20 vezes e capturados pelo programa Alpha Digi Doc $1201^{\circledR}$, obtendo-se no final três imagens de cada lâmina. Cada imagem foi dividida em dez partes iguais e a fibra muscular, em corte transversal, que se localizava no centro de cada divisão foi escolhida para mensuração da área por meio do programa Alfa Easer FC $^{\circledR}$. Uma vez obtidas as áreas das fibras das três imagens, efetuou-se a média entre elas para posterior análise estatística.

Com os resultados obtidos, aplicou-se análise de variância de uma via, seguida de teste Duncan de comparações múltiplas. Todos os resultados foram indicados pela média \pm do erro padrão da média (EPM).

\section{RESULTADOS E DISCUSSÃO}

O método de fixação esquelética externa tipo II foi empregado nesta pesquisa para imobilizar o joelho por um período de 30 dias, o que proporcionou o desuso do membro e ocasionou atrofia principalmente dos músculos da coxa. A atrofia muscular foi também encontrada por Mazzanti et al. (2004); Salbego (2006); Brendolan et al. (2007) e Penha et al., (2007) ao imobilizarem a articulação do joelho em cães, após artroplastia do mesmo. O uso da imobilização e conseqüente desuso do membro foram também empregados em outros estudos para ocasionar atrofia muscular (Morrissey et al., 1985; Appell, 1986; Gossman et al., 1986; Snyder-Mackler et al., 1991).

Evangelista et al. (2003) utilizaram a EENM, com freqüência modulada em $50 \mathrm{~Hz}$, em desempenho no teste de aptidão física em humanos e observaram melhora na estrutura muscular, bem como redução do percentual de tecido adiposo. A freqüência utilizada de $50 \mathrm{~Hz}$ teve como base essa informação e o tipo de fibras musculares que predominam nos músculos estimulados neste experimento. Armstrong et al. (1982) demonstraram que nos músculos que compõem o quadríceps femoral, com exceção do vasto intermédio, predominam as fibras tipo II, ou seja, de contração rápida, sendo citado por Envangelista et al. (2003) que a freqüência ideal para contração destas fibras encontra-se entre 50 e $150 \mathrm{~Hz}$. Pérez et al. (2002), ao empregarem a estimulação elétrica no músculo quadríceps em humanos numa freqüência entre $45-60 \mathrm{~Hz}$ durante 30 minutos, observaram hipertrofia do músculo vastolateral, aumento da capacidade oxidativa e do número de capilares, principalmente nas fibras do tipo II.

Os cães de ambos os grupos atingiram o retorno funcional do membro (grau V) entre o $19^{\circ}$ e o $54^{\circ}$ dias após a retirada da imobilização, não havendo diferença significativa entre os grupos. A imobilização externa rígida temporária em flexão e a ausência de cirurgia articular provavelmente tiveram influência positiva neste resultado, confirmando os resultados de Souza (2006). Millis (2004) afirmou que a imobilização em extensão resultou em maior espasticidade muscular e aumentou o tempo de recuperação funcional do membro, resultado também encontrado por Mazzanti (2002), que imobilizou o joelho em extensão após artroplastia.

Uma das causas na diminuição da amplitude de movimento articular ocorre pelo espasmo 
muscular em decorrência da imobilização prolongada, o que pode gerar dor e o não apoio do membro ao solo. Embora a EENM tenha como indicação a redução do espasmo muscular (Millis, 2004), não houve diferença estatística entre os grupos I e II quanto à amplitude de movimento articular decorridos 90 dias da imobilização da articulação do joelho, demonstrando que a EENM não teve influência neste parâmetro avaliado. Resultados similares foram encontrados por Salbego (2006) ao reconstruir o ligamento cruzado cranial em cães.

Os valores da circunferência da coxa variaram no pós-operatório, porém, não apresentaram diferença significativa entre os grupos controle e tratado decorridos 90 dias da imobilização da articulação do joelho. Resultados semelhantes também foram verificados por Johnson et al. (1997) quando utilizaram esse parâmetro para avaliar a recuperação da massa muscular em cães submetidos à EENM após a reconstrução do ligamento cruzado cranial. Os autores comentaram que o aumento de ganho na espessura da coxa significa uma elevação na força muscular, mas que é de difícil avaliação nos cães, pois necessita do uso do dinamômetro em máxima contração voluntária, limitando o seu uso em animais. Quando se utiliza esse tipo de parâmetro, deve-se enfatizar o grau de edema em que o membro estudado se encontra principalmente no pós-cirúrgico imediato, tornando-se subjetivo este tipo de análise, e a variação dos valores encontrados pode não refletir o ganho de massa muscular.

A biópsia do músculo vasto lateral foi de fundamental importância para estudar o efeito da EENM, já que os demais parâmetros não demonstraram diferença entre os grupos. Embora a técnica de biópsia muscular com agulha seja indicada para avaliar o ganho de massa muscular (Pérez et al., 2002), um problema verificado neste estudo foi o tamanho limitado dos fragmentos colhidos, fato também encontrado por Dickinson e LeCouteur (2002). Gibson et al. (1988) e Pérez et al. (2002), ao colherem amostras do músculo vasto lateral em humanos, com peso aproximado de $100 \mathrm{mg}$, não observaram limitação quanto ao tamanho e processamento dos fragmentos musculares.

Não foi detectada nenhuma complicação decorrente da biópsia muscular, como hemorragia e infecção, à semelhança de Reynolds et al. (1995). No entanto, foi notada em todos os animais dos grupos I e II interferência no grau de claudicação, que se normalizou, em média, no terceiro dia após a biópsia.

Quanto ao valor das áreas obtidas dos cortes transversais das fibras musculares, não se verificou diferença estatística entre os grupos controle e tratado. Porém, ao se comparar as medidas das áreas entre os tempos (zero, 30 e 90 dias) em cada grupo, foi observada somente nos animais do grupo tratado diferença estatisticamente significativa $(P<0,05)$ entre os tempos zero (antes da imobilização) e 90 dias da imobilização articular (Fig. 1). Isso demonstra que a EENM durante 60 dias promoveu o ganho de massa muscular, corroborando com os achados obtidos por Gibson et al. (1988) e Snyder-Mackler et al. (1991).

O ciclo de estimulação de 1:2 (12 segundos "on" e 25 segundos "off") utilizado foi recomendado por Johnson e Levine (2004) para evitar a fadiga muscular gerada pela contração muscular. Como método de avaliar a fadiga muscular, pode-se citar a mensuração das atividades enzimáticas, como a CK demonstrada por Dahlstedt et al. (2000), bem como os sinais clínicos de dor gerada pelo acúmulo de substâncias do metabolismo celular conforme descrito por Westerblad et al. (1998).

Os resultados das análises da enzima CK e AST séricas não demonstraram diferença estatisticamente comprovada entre os dois grupos. Os valores encontrados não foram suficientemente elevados para sugerir a ocorrência de lesões nas fibras musculares ou fadiga muscular, como citado por Johnson e Levine (2004). Isso pode ser justificado pela escolha da relação "on timeloff time" de 1:2, no tempo de estimulação utilizada no experimento, o que daria tempo para a recomposição da fosfogenase. Essa enzima foi citada por Evangelista et al. (2003) como necessária para a contração muscular e, que durante a EENM, pode ser consumida em 15 segundos. A duração para o seu reabastecimento imediato pode ser de 22 segundos. Esse tempo é próximo ao citado por Brasileiro et al. (2002) em que o descanso ideal (off time) deve ser de aproximadamente 60 segundos para evitar a fadiga muscular. 


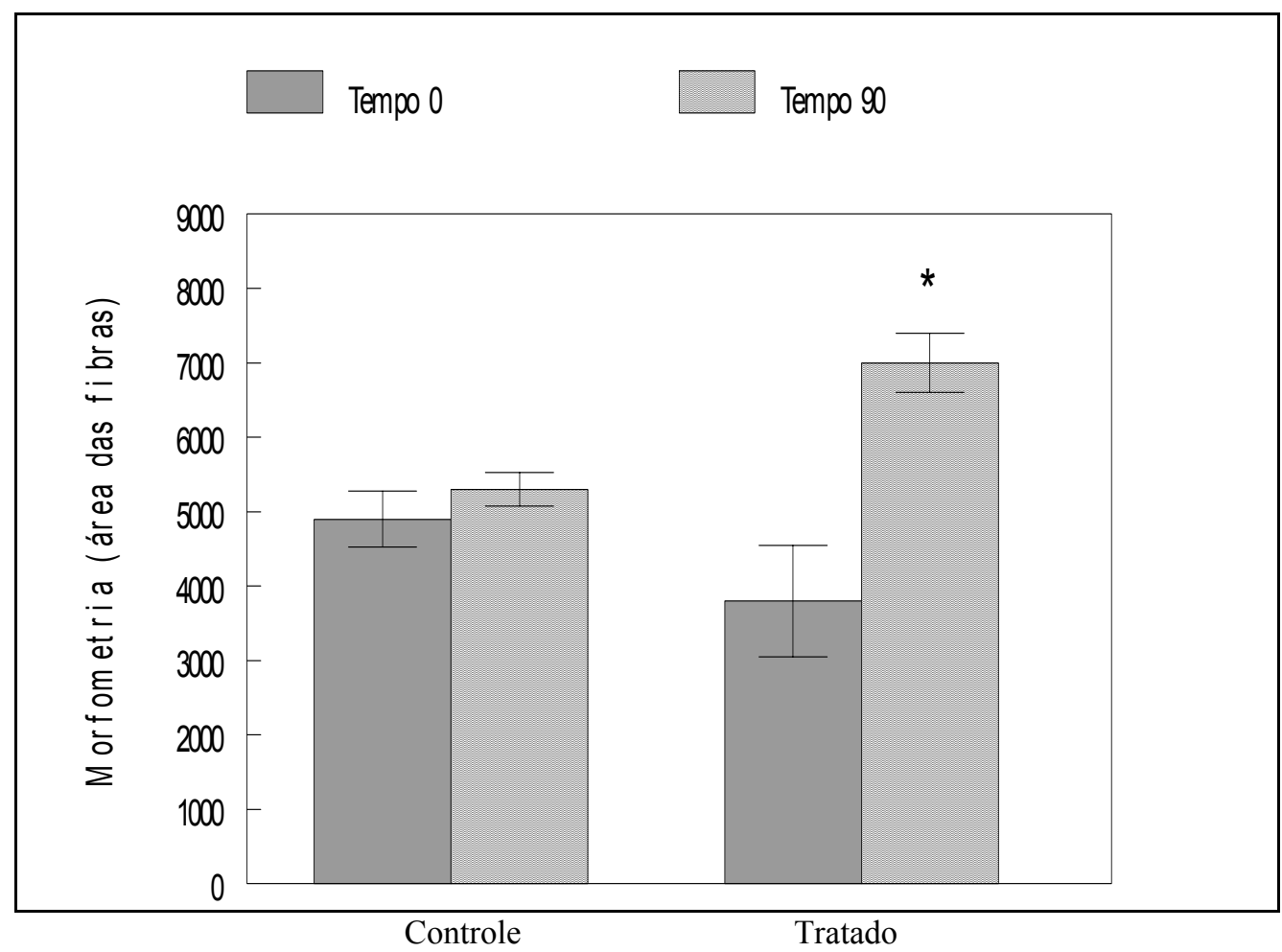

Figura 1. Morfometria das fibras musculares em corte transversal (área) de cães com atrofia muscular induzida nos tempos zero e 90, submetido (tratado) ou não (controle) a estimulação elétrica neuromuscular de baixa freqüência. A área das fibras foi mensurada pelo programa Alfa Ease $\mathrm{FC}^{\circledR}$, e seus valores são referidos em pixels. $\left.{ }^{*}\right)$ Significância estatística $(\mathrm{P}<0,05)$.

\section{CONCLUSÕES}

Diante dos resultados obtidos, pode-se concluir que o modelo de imobilização rígida temporária da articulação do joelho induz atrofia dos músculos da coxa, permitindo avaliar o efeito da EENM de baixa freqüência nos músculos do quadríceps femoral. A EENM ocasiona hipertrofia do músculo vastolateral.

\section{AGRADECIMENTO}

Ao Conselho Nacional de Desenvolvimento Científico e Tecnológico (CNPq), pelo financiamento da pesquisa vinculada ao processo 550866/2002-7.

\section{REFERÊNCIAS BIBLIOGRÁFICAS}

APPELL, H.J. Skeletal muscle atrophy during immobilization. Intern. J. Sports Med., v.7, p.6-12, 1986.

ARMSTRONG R.B., SAUBERT C.W., SEEHERMAN H.J. et al. Distribution of fiber types in locomotory muscles of dogs. Am. J. Anat., v.163, p.87-98, 1982.

ARON, D.N. Tendões. In: BOJRAB, M.J. (Ed). Técnicas atuais em cirurgia de pequenos animais. 3.ed. São Paulo: Roca, 1996. cap.40, p.516-527.

BRASILEIRO, J.S.; CASTRO, C.E.S.C.; PARIZOTTO, N.A. Parâmetros manipuláveis clinicamente na estimulação elétrica neuromuscular (EENM). Fisioter. Brasil., v.3, p.16-24, 2002.

BRENDOLAN, A.P.; REZENDE, C.M.F.; MELO, E.G. et al. Aspectos clínicos e radiográficos do pericárdio bovino como substituto do ligamento cruzado cranial de cães. Arq. Bras. Med. Vet. Zootec., v.59, p.920-921, 2007.

DAHLSTEDT, A.J.; KATZ. A.; WIERINGA. B. et al. Is creatine kinase responsible for fatigue? Studies of isolated skeletal muscle deficient in creatine kinase. Faseb J., v.14, p.982-990, 2000.

DICKINSON, P.J.; LeCOUTEUR, A.R. Muscle and neve biopsy. Vet. Clin. N. Am.: Small Anim. Pract., v. 32, p.68, 2002. 
EVANGELISTA, R.A.; GRAVINA, G.A.; BORGES, F.S. et al. Adaptação da característica fisiológica da fibra muscular por meio de eletroestimulação. Fisioter. Brasil., v.4, p.326-334, 2003.

GIBSON, G.; SMITH, K.; RENNIE, M.J. Prevention of difuse muscle atrophy by means of electrical stimulation: maintenance of protein synthesis. Lancet, v.2, p.767-770, 1988.

GOULD, N.; DONNERMEYER, D., GAMMON, G.G. et al. Transcutaneous muscle stimulation to retard disuse atrophy after open meniscectomy. Clin. Orthop. Relat. Res., v.9, p.190-197, 1983.

GOSSMAN, M.R.; ROSE, S.J.; SAHRMANN, S.A. et al. Length and circumference measurements in one-joint and multijoint muscle in rabbits after immobilization. Phys. Ther., v.66, p.516-520, 1986.

JOHNSON, J.; LEVINE, D. Electrical stimulation. In: MILLIS, D.L.; LEVINE, D.; TAYLOR, R.A. (Eds). Canine rehabilitation \& physical therapy. Missouri: Elsevier, 2004. cap.17, p.289-302.

JOHNSON, J.M.; JOHNSON, A.L.; PIJANOWSKI, G.J. et al. Rehabilitation of dogs with surgically treated cranial cruciate ligamentdeficient stifles by use of electrical stimulation of muscles. Am. J. Vet. Res., v.58, p.1473-1478, 1997.

KITCHEN, S. (Ed). Eletroterapia. Prática baseada em evidência. 11.ed. São Paulo: Manole, 2003. 348p.

MAZZANTI, A. Homoimplante ortotópico conservado, associado à terapia "soft laser" na reparação tenopatelar em cão. 2002. 80f. Tese (Doutorado) - Universidade Federal de Santa Maria, Santa Maria, RS.

MAZZANTI, A.; RAISER, A.G.; PIPPI, N.L. et al. Homoimplante ortotópico conservado, associado à terapia "soft laser" na reparação tenopatelar em cão. Cienc. Rural, v.34, p.429-437, 2004.

MILLIS, D.L. Responses of musculoskeletal tissues to disuse and remobilization. In: MILLIS, D.L.; LEVINE, D.; TAYLOR, R.A. (Eds). Canine rehabilitation \& physical therapy. Missouri: Elsevier, 2004. cap.7, p.113-159.

MORRISSEY, M.C.; BREWSTER, C.E.; SHIELDS, L.C. et al. The effects of electrical stimulation on the quadriceps during postoperative knee immobilization. Am. J. Sports Med., v.13, p.40-45, 1985.
PENHA, E.M.; C.M.F. REZENDE; MELO, E.G. et al. Pós-operatório tardio da substituição do ligamento cruzado cranial no cão. Arq. Bras. Med. Vet. Zootec., v.59, p.1184-1193, 2007.

PEREZ, M.; LUCIA, A.; RIVERO, J.L. et al. Effects of transcutaneous short-term electrical stimulation on M. vastus lateralis characteristics of healthy young men. Pflugers Arch., v.443, p.866874, 2002.

REYNOLDS, A.J.; FUHRER, L.; VALENTINE, B.A. et al. New approach to percutaneous muscle biopsy in dogs. Am. J. Vet. Res., v.56, p.982-985, 1995.

SALBEGO, F.Z. Substituição do ligamento cruzado cranial em cães, por segmento teno-ósseo homólogo conservado em glicerina a 98\%, submetidos a diferentes protocolos de reabilitação. 2006. 119f. Dissertação (Mestrado) - Escola de Veterinária, Universidade Federal de Santa Maria, Santa Maria, RS.

SOUZA, S.F. Estimulação elétrica neuromuscular em cães submetidos à imobilização rígida temporária da articulação femorotibiopatelar. 2006. 81f. Dissertação (Mestrado) - Escola de Veterinária, Universidade Federal de Santa Maria, Santa Maria, RS.

SALTER, A.C.; RICHMOND, F.J.; LOEB, G.E. Prevention of muscle disuseatrophy by lowfrequency electrical stimulation in rats. IEEE Trans Neural Syst. Rehabil. Eng., v.11, p.218-226, 2003.

SNYDER-MACKLER, L.; LADIN, Z.; SCHEPSIS, A.A. et al. Electrical stimulation of the thigh muscles after reconstruction of the anterior cruciate ligament. J. Bone Jt. Surg. Am., v.73, p.1025-1034, 1991.

THOMSON, F.K.; BOWEN, J.M. Eletrodiagnostic testing: mapping and clinical use of motor points in the dog. J. Am. Vet. Med. Assoc., v.159, p.17631771, 1971.

TUDURY, E.A.; RAISER, A.G. Redução de fraturas distais de fêmur em cães, empregando pinos de Steinmann em substituição aos de Rush. Cien. Rural, v.15, p.141-155, 1985.

WESTERBLAD, H.; ALLEN, D.G.; BRUTON, J.D. et al. Mechanisms underlying the reduction of isometric force skeletal muscle fatigue. Acta Physiol. Scand., v.162, p.253-260, 1998. 